\title{
The Internal Relation between Credence Goods, Consumer Perceived Value and Enterprise Performance
}

\author{
Fuyong Lu ${ }^{1}$, Xintao Wang ${ }^{2, *}$ \\ ${ }^{1}$ Academy of China Open Economy Studies, University of International Business and Economics, Beijing 100105, China. \\ ${ }^{2}$ School of Business, Renmin University of China, No. 59, Zhongguancun Street, Haidian District, Beijing 100872, China.
}

How to cite this paper: Fuyong Lu, Xintao Wang. (2021) The Internal Relation between Credence Goods, Consumer Perceived Value and Enterprise Performance. Journal of Humanities, Arts and Social Science, 5(2), 275-280.

DOI: $10.26855 /$ jhass.2021.07.012

Received: October 22, 2021

Accepted: November 18, 2021

Published: December 16, 2021

*Corresponding author: Xintao Wang, School of Business, Renmin University of China, No. 59, Zhongguancun Street, Haidian District, Beijing 100872, China.

Email: 2017103654@ruc.edu.cn

\begin{abstract}
At present, there is significant information asymmetry in the credence goods market, which causes difficulties in market supervision, consumers' choice and enterprises' reverse elimination. The release of credence goods signals enhances the perceived value of consumers, thus increasing the propensity to consume and further improving enterprise performance. This paper takes tea, a typical trusted product, as the empirical research object, and collects a wide range of data samples to study how consumers who lack effective information perceive the mapping value of credence goods and how it affects the business performance of enterprises. The results show that credence goods improve enterprise performance through social value, functional value, investment value and service value, which affect consumers' attention. From the empirical level, this paper reveals that the commodity attribute of credence goods determines the degree of market information asymmetry to a certain extent, and the business performance of enterprises is inseparable from the effective transmission of information under the guidance of market price mechanism. The research further puts forward some suggestions and inspirations for enterprises' product development in information asymmetric market.
\end{abstract}

\section{Keywords}

Credence goods, Information asymmetry, The release of signal, Consumer perceived value, Enterprise performance

\section{Problem}

According to the theory of industrial organization, credence goods refer to those products whose quality is still hard for consumers to confirm after enjoying, such as health care products, edible agricultural products, etc., and a number of products with inadequate disclosure of quality. And plenty of problems in the credence goods market are caused by information asymmetry between buyers and sellers. The seller keeps more product information, and it is inconvenient for consumers to identify product quality in a short time. Therefore, market failure and high transaction cost generated by information asymmetry accelerate market "reverse elimination". Some agricultural products have typical characteristics of credence goods, such as tea products, and it is tough to achieve standardization, management standardization and information standardization in the production process. And the disclosure of product quality information and production process information is insufficient, which makes it confusing for consumers to judge the grade of products, and creates the opportunity for enterprises producing inferior products. Cre- 
dence goods may incapable of meeting the quality requirements of consumers and cause sellers to lose consumer stickiness. In particular, high-quality products cannot play a positive role in consumers' willingness (Hackmann et al., 2015). Information asymmetry has brought about some market segmentation, and strengthening market regulation may have little effect (Dulleck et al., 2011). Hence, for enterprises, seeking a more appropriate way to release quality information is the key to solve the problem of credence goods market.

\section{Theoretical basis and research hypothesis}

The root of trust problem is information asymmetry between buyer and seller. In fact, consumers may judge by other relevant information when they are confused about the quality evaluation of credence goods. In the credence goods market, product quality signals and consumers' perceived value will affect its sales to a certain extent, thus affecting enterprise performance.

\subsection{Credence goods and Enterprise performance}

Information asymmetry in the credence goods market is frequently accompanied by adverse selection and moral hazard, leading to "bad money driving out good money" at the enterprise level. Enterprises that produce high-quality products are unable to compete with those that produce inferior products, and are even expelled from the market. Due to the high difficulty of market supervision, adverse market selection aggravates the dilemma of enterprise operation in places with high degree of marketization. Although companies that produce inferior products may profit speculatively, this situation will not last long; enterprises that produce high-quality products are capable of shaping corporate image and improving corporate performance through product quality and brand reputation (Yang Kun \& Xiao Shuyu, 2011). Therefore, enterprises in the credence goods market improve their performance by releasing product signals.

\subsection{Credence goods and consumer perceived value}

Consumer perception refers to the process in which consumers receive external information and map it to their own needs (Spiller \& Belogolova, 2017). Consumers' perception varies with the vertical difference of products, and different choices represent diversified value satisfaction. Consumers make rational choices based on value information (Legros \& Newman, 2013) to maximize their utility preferences. However, consumers' shopping choices are based on product information in a specific environment. When credence goods only display part of product quality information, it is prudent to demonstrate more environmental information reflecting product quality, so that consumers have a choice to make a tradeoff of perceived value according to their actual needs. Hence, the release of credence goods signals improves consumers’ perceived value.

\subsection{Consumer perceived value and Enterprise performance}

Consumer perceived value is composed of a series of information of consumption tendency, which determines the consumer's consumption tendency. The richer the consumer's perceived value is in the consumer's consumption tendency, the higher the consumer's consumption tendency will be. Consumers' perceived value affects their purchase of products, especially for non-first-time customers, which increase consumer stickiness and brand satisfaction. Consumer perceived value corresponds to customer value and consumer perception. Customers with more diversified consumption tend to bring higher income and performance to enterprises (Dai et al., 2020). In the credence goods market, consumers' perceived value reduces market transaction costs to some extent through heterogeneous consumption propensity (Alsan et al., 2019) and improves transaction efficiency.

Based on the above analysis, the following hypotheses are proposed:

Hypothesis $\mathrm{H}_{1}$ : The effective release of credence goods signal improve enterprise performance.

Hypothesis $\mathrm{H}_{1 \mathrm{a}}$ : External signals of credence goods improve enterprise performance more effectively than internal signals of credence goods.

Hypothesis $\mathrm{H}_{2}$ : The effective release of credence goods signal increase the perceived value of consumers.

Hypothesis $\mathrm{H}_{3}$ : The increase of consumer perceived value improve the performance of agricultural enterprises.

The research path of this paper is shown in Figure 1. 


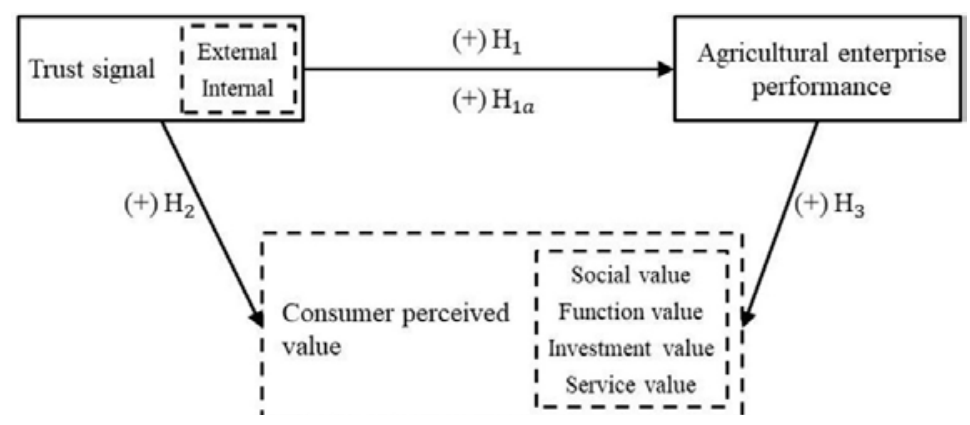

Figure 1. The mechanism of credence goods signal on the performance of agricultural enterprises.

\section{Data analysis and empirical model}

\subsection{Data analysis}

\subsubsection{Variable structure and source description}

Tea is a kind of typical credence goods. This paper selects tea enterprises and consumers as research objects and collects a series of indicators for empirical analysis. See Table 1 for the structure and description of related variables.

Table 1. Variable Structure and Source Description

\begin{tabular}{|c|c|c|}
\hline Variable categories & $\begin{array}{l}\text { Variable } \\
\text { symbol }\end{array}$ & Variable declaration \\
\hline Credence goods signal & signaling & Whether the corresponding product signal is available \\
\hline External signal & outsig & $\begin{array}{l}\text { Whether it has the quality signal of the product manufacturer, the quality sig- } \\
\text { nal of the product merchant and the quality certification signal of the third } \\
\text { party }\end{array}$ \\
\hline Internal signal & insig & Whether it has product function value, product use value, etc \\
\hline Enterprise performance & achieve & Product sales income of the enterprise \\
\hline Consumer perceived value & emotion & Value preference information of consumers in market transactions \\
\hline Social value & social & $\begin{array}{l}\text { Whether consumers pay attention to interpersonal communication, social } \\
\text { communication and other attributes of product }\end{array}$ \\
\hline Function value & quality & $\begin{array}{c}\text { Whether consumers pay attention to the use function, quality performance and } \\
\text { other values of the product }\end{array}$ \\
\hline Investment value & invest & $\begin{array}{l}\text { Whether consumers care about the value of products such as investment or } \\
\text { speculation }\end{array}$ \\
\hline Service value & service & $\begin{array}{l}\text { Whether consumers pay attention to the value of follow-up service, safety and } \\
\text { environmental protection }\end{array}$ \\
\hline Control variables & control & A collection of other variables that may affect the signaling of credence goods \\
\hline Gender & gender & Consumer gender \\
\hline Age & age & Consumer age \\
\hline Province & province & Location of consumer \\
\hline Type & type & Consumer type, classified as first-time or repeat buyers \\
\hline Product grade & grade & The grade of enterprise products, divided into high, medium and low \\
\hline $\begin{array}{l}\text { The number of years for the enter- } \\
\text { prise to carry out business }\end{array}$ & experience & The number of years for the enterprise to carry out business \\
\hline The number of core customers & vip & The number of core customers \\
\hline Staff training duration & train & Employee training hours/year organized by the enterprise \\
\hline Value returned to customers & treat & Value returned by the enterprise to the customer/year \\
\hline Expenditure on cultural promotion & culture & Enterprise culture publicity expenditure/year \\
\hline
\end{tabular}




\subsubsection{Statistical description}

The data covered tea sales markets in eight provinces in eastern, central and western China, with 1,221 data samples obtained. Detailed variable descriptions are shown in Table 2.

Table 2. Descriptive statistics of variables

\begin{tabular}{|c|c|c|c|c|c|}
\hline Variable & Sample size & Mean & Standard deviation & Minimum & Maxmium \\
\hline signaling & 1221 & 0.36 & 0.10 & 0 & 1 \\
\hline outsig & 1221 & 0.41 & 0.11 & 0 & 1 \\
\hline insig & 1221 & 0.26 & 0.10 & 0 & 1 \\
\hline income & 1221 & 0.15 & 0.07 & 0 & 1 \\
\hline emotion & 1221 & 0.49 & 0.02 & 0 & 1 \\
\hline social & 1221 & 0.84 & 2.09 & 0 & 1 \\
\hline quality & 1221 & 0.65 & 2.21 & 0 & 1 \\
\hline invest & 1221 & 0.29 & 0.04 & 0 & 1 \\
\hline service & 1221 & 0.19 & 0.08 & 0 & 1 \\
\hline gender & 1221 & 0.42 & 0.27 & 0 & 1 \\
\hline age & 1221 & 39.31 & 0.14 & 19 & 63 \\
\hline type & 1221 & 0.48 & 0.10 & 0 & 1 \\
\hline grade & 1221 & 1.38 & 0.47 & 0 & 2 \\
\hline experience & 1221 & 4.64 & 2.65 & 0.5 & 11 \\
\hline vip & 1221 & 46.34 & 17.35 & 35 & 715 \\
\hline train & 1221 & 13.45 & 22.72 & 2.08 & 186.92 \\
\hline treat & 1221 & 10.68 & 8.36 & 0.21 & 86.79 \\
\hline culture & 1221 & 366.11 & 214.94 & 87.17 & 636.67 \\
\hline
\end{tabular}

\subsection{Empirical model}

Based on theoretical analysis, the benchmark regression model is set as follows:

$$
\text { lnincome }_{i t}=\gamma \text { lnsignaling }_{i t}+X_{i t}^{\prime} \phi+\alpha_{i}+\lambda_{t}+\mu_{i t}
$$

lnincome $e_{i t}$ represents the business revenue in logarithmic form, the subscripting $i$ and $t$ represent the business and year respectively, lnsignaling ${ }_{i t}$ represents the trust quality signal strength in logarithmic form, $\gamma$ is the signal strength coefficient in logarithmic form of the explanatory variable, $X_{i t}^{\prime}$ is the matrix representation of the remaining control variables of the equation, $\phi$ represents the coefficient vectors of the remaining governing variables of the equation, $\alpha_{i}$ and $\lambda_{t}$ are the enterprise fixed effect and time fixed effect, respectively, and $\mu_{i t}$ is the random disturbance term.

In this paper, the mediating variable of the characteristic variable of consumer perceived value is added to emphasize the mechanism of trust quality signal on the performance of agricultural enterprises. The regression model is set as follows:

$$
\begin{aligned}
& \text { lnincome }_{i t}=\delta_{1} \text { lnemotion }_{i t}+X_{i t}^{\prime} \phi+\alpha_{i}+\lambda_{t}+\mu_{i t} \\
& \text { lnemotion }_{i t}=\delta_{2} \text { Insignaling }_{i t}+X_{i t}^{\prime} \phi+\alpha_{i}+\lambda_{t}+\mu_{i t}
\end{aligned}
$$

Among them, lnecodex $x_{i t}$ represents the market activity index of the region where the enterprise is located in logarithmic form, lninfomatch form, $\delta_{1} \delta_{2}$ represents the influence effect of trust quality signal.

\section{Empirical results analysis}

\subsection{Empirical regression analysis}

The results in Column (1) of Table 3 are significantly positive, indicating that the effective release of credence goods signal will significantly improve enterprise performance. Hypothesis $\mathrm{H}_{1}$ has been verified. Columns (2) and 
(3) respectively reflect that external and internal signals of credence goods have a positive impact on corporate performance, and the empirical results verify the hypothesis $\mathrm{H}_{1 \mathrm{a}}$. Columns (4) to (8) verify the impact of consumer perceived value on enterprise performance, indicating that credence goods signals can improve enterprise performance through consumer perceived effect, and the impact of consumer perceived social value and functional value on enterprise performance is more significant than that of investment value and service value. Hypothesis $\mathrm{H}_{3}$ is verified.

Table 3. Product quality signals and adverse selection of agricultural enterprises

\begin{tabular}{|c|c|c|c|c|c|c|c|c|}
\hline & (1) & (2) & (3) & (4) & (5) & (6) & (7) & (8) \\
\hline lnsignaling & $\begin{array}{c}0.335^{* * *} \\
(10.23)\end{array}$ & & & & & & & \\
\hline lnoutsig & & $\begin{array}{c}0.452^{* * *} \\
(8.33)\end{array}$ & & & & & & \\
\hline lninsig & & & $\begin{array}{c}0.323^{* * *} \\
(9.72)\end{array}$ & & & & & \\
\hline lnemotion & & & & $\begin{array}{c}0.414^{* * *} \\
(12.13)\end{array}$ & & & & \\
\hline Insocial & & & & & $\begin{array}{l}0.242^{*} \\
(0.42)\end{array}$ & & & \\
\hline lnquality & & & & & & $\begin{array}{c}0.505^{* * *} \\
(13.54)\end{array}$ & & \\
\hline lninvest & & & & & & & $\begin{array}{c}0.390^{* * *} \\
(4.83)\end{array}$ & \\
\hline lnservice & & & & & & & & $\begin{array}{c}0.333^{* * *} \\
(4.68)\end{array}$ \\
\hline $\mathrm{N}$ & 1221 & 1221 & 1221 & 1221 & 1221 & 1221 & 1221 & 1221 \\
\hline adj. R2 & 0.865 & 0.876 & 0.853 & 0.926 & 0.969 & 0.935 & 0.926 & 0.969 \\
\hline Control & Yes & Yes & Yes & Yes & Yes & Yes & Yes & Yes \\
\hline Province & Yes & Yes & Yes & Yes & Yes & Yes & Yes & Yes \\
\hline Year & Yes & Yes & Yes & Yes & Yes & Yes & Yes & Yes \\
\hline
\end{tabular}

$t$ statistics in parentheses; ${ }^{*} p<0.1,{ }^{* *} p<0.05,{ }^{* * *} p<0.01$

The results in Column (4) of Table 4 show that the effective release of credence goods signal has a significant positive impact on consumers' perceived value, and its impact on consumers' social perceived value, functional perceived value, investment perceived value and service perceived value are all significantly positive, which verifies hypothesis $\mathrm{H}_{2}$.

Table 4. Product quality signal and consumer perceived value

\begin{tabular}{|c|c|c|c|c|c|}
\hline & lnemotion & lnsocial & lnquality & lninvest & lnservice \\
\hline \multirow{2}{*}{ lnsignaling } & $0.362^{* * * *}$ & $0.452^{* * *}$ & $0.323^{* * *}$ & $0.505^{* * *}$ & $0.390^{* * * *}$ \\
\hline & $(9.44)$ & (8.33) & (9.72) & (13.54) & (4.83) \\
\hline $\mathrm{N}$ & 1221 & 1221 & 1221 & 1221 & 1221 \\
\hline adj. R2 & 0.841 & 0.895 & 0.867 & 0.976 & 0.979 \\
\hline Control & Yes & Yes & Yes & Yes & Yes \\
\hline Province & Yes & Yes & Yes & Yes & Yes \\
\hline Year & Yes & Yes & Yes & Yes & Yes \\
\hline
\end{tabular}

$t$ statistics in parentheses; ${ }^{*} p<0.1,{ }^{* *} p<0.05,{ }^{* * *} p<0.01$ 


\subsection{Robustness test}

The empirical analysis controls for the influence of enterprise characteristics and consumer characteristics, and further reduces the influence of endogeneity through fixed effects. This paper conducts a multidimensional test on the mechanism of credence goods signal affecting enterprise performance, and makes an empirical analysis by using enterprise product quality certification information as a substitute variable of trustworthiness signal (Zhou Jiehong, 2020). The results show that credence goods signal still has a significant positive impact on enterprise performance. In the mediation effect analysis, the effect of the mediation variable passed the Bootstrap test, which further demonstrated the robustness of the results.

\section{Conclusions and Implications}

In this paper, credence goods, consumer perceived value and enterprise performance are incorporated into the unified model framework, and the relationship between credence goods signal release and enterprise performance is studied. The mediating variable with consumer perceived value as the core is constructed, and the mechanism of trust signal influencing enterprise performance is explained. The results show that the effective release of trust signal can significantly improve enterprise performance, and the external signal of trust signal can improve enterprise performance more effectively than the internal signal. Consumer perceived value is an important transmission mechanism for trustworthiness signals to influence enterprise performance.

This paper draws the following implications: First of all, in the credence goods market, adverse selection phenomenon is seriously rooted in the lack of product information disclosure. It is fundamental to constantly improve the information standardization construction and disclosure mechanism of credence goods, and both industry self-discipline and market supervision need to be further strengthened. Secondly, in credence goods market, in order to prevent reverse elimination, enterprises producing high-quality products should pay attention to diversified perceived value of consumers, release multi-dimensional product signals and improve consumer stickiness. Thirdly, to solve the problem of information asymmetry in the trust product market, there should be a standardized information release mechanism (Seim \& Waldfogel, 2013), as well as perfect legal and regulatory guarantee.

\section{Funding}

Special Funds for Fundamental Scientific Research Business Expenses of Central Universities of University of International Business and Economics (16QD14).

\section{References}

Alsan, M., Garrick, O., Graziani, G. (2019). Does diversity matter for health? Experimental evidence from Oakland [J]. American Economic Review, 2019, 109(12): 4071-4111.

Dai, H., Chan, C., Mogilner, C. (2020). People rely less on consumer reviews for experiential than material purchases [J]. Journal of Consumer Research, 2020, 46(6): 1052-1075.

Dulleck, U., Kerschbamer, R., Sutter, M. (2011). The economics of credence goods: An experiment on the role of liability, verifiability, reputation, and competition [J]. American Economic Review, 2011, 101(2): 526-55.

Hackmann, M. B., Kolstad, J. T., Kowalski, A. E. (2015). Adverse selection and an individual mandate: When theory meets practice [J]. American Economic Review, 2015, 105(3): 1030-66.

Legros, P., Newman, A. F. (2013). A price theory of vertical and lateral integration [J]. The Quarterly Journal of Economics, 2013, 128(2): 725-770.

Seim, K., Waldfogel, J. (2013). Public monopoly and economic efficiency: evidence from the Pennsylvania liquor control board's entry decisions [J]. American Economic Review, 2013, 103(2): 831-62.

Spiller, S. A., Belogolova, L. (2017). On consumer beliefs about quality and taste [J]. Journal of Consumer Research, 2017, 43(6): 970-991.

Zhou Jiehong, Jin Yu, Wang Yu, Liang Qiao. (2020). Quality information disclosure, signal transmission and agricultural product certification: A comparative analysis based on meat and vegetable industry [J]. Issues in Agricultural Economy, 2020(09): 76-87. 